\title{
Oncogenes and senescence: breaking down in the fast lane
}

\author{
Michael T. Hemann ${ }^{1,3}$ and Masashi Narita ${ }^{2,4}$ \\ ${ }^{1}$ Center for Cancer Research, Massachusetts Institute of Technology, Cambridge, Massachusetts 02139, USA; ${ }^{2}$ Cancer \\ Research United Kingdom, Cambridge Research Institute, Cambridge CB2 ORE, United Kingdom
}

\begin{abstract}
Aberrant oncogene expression is the driving force behind the development of all cancers. Consequently, robust tumor suppressive processes have evolved in multicellular organisms to recognize and counteract the malignant potential of individual cells harboring deregulated oncogenes. These processes prevent tumor development by directing cells with inappropriate proliferative signals toward distinct terminal states, including cell death and an irreversible form of cell cycle arrest called cellular senescence (Lowe et al. 2004). While much of the cellular machinery that executes these tumor suppressive functions is known, the "oncogenic signals" that engage this machinery are less understood. In this issue of Genes \& Development, Ferbeyre and colleagues (Mallette et al. 2007) provide new insight into this process, implicating oncogene-induced DNA damage signaling as a critical instigator of oncogene-induced senescence.
\end{abstract}

\section{DNA damage as an oncogenic signal}

The overexpression or activation of growth-promoting genes is essential for cancer development, yet normal cells are hard-wired to recognize inappropriate proliferative signals. This cellular sensitivity to oncogenes was first recognized in cells engineered to overexpress $c-M y c$ or the viral oncogene E1A. While these "immortalized" oncogene-expressing cells grew more rapidly, they also became exquisitely sensitive to cell death stimuli and failed to transform (Evan et al. 1992; Lowe and Ruley 1993). Thus, oncogene overexpression could concurrently promote cell growth and cell death. Subsequently, experiments using an activated variant of the Ras oncoprotein showed that mutant Ras also failed to transform normal cells. Rather, enforced Ras expression induced a transient increase in cell proliferation followed by a stable cell cycle arrest termed cellular senescence (Serrano et al. 1997).

While senescence and apoptosis represent dramatically different cellular responses to deregulated oncogene expression, they can be initiated through the acti-

Correspondence.

${ }^{3}$ E-MAIL hemann@mit.edu; FAX (617) 252-1891.

${ }^{4}$ E-MAIL masashi.narita@cancer.org.uk; FAX 44-0-1223-404208.

Article is online at http://www.genesdev.org/cgi/doi/10.1101/gad.1514207. vation of a common tumor suppressor network. Specifically, studies in primary murine fibroblasts have convincingly shown that the induction of the tumor suppressor p53 and its positive regulator ARF are required to promote apoptosis and senescence and, consequently, prevent oncogene-induced transformation (de Stanchina et al. 1998; Palmero et al. 1998; Zindy et al. 1998). This work led to the canonical model of oncogenic signaling, by which inappropriate proliferative signals are "sensed" by ARF, leading to p53 stabilization and the transcriptional up-regulation of apoptotic or cytostatic p53 target genes. Importantly, this model suggests that DNA damage is not the primary signal emanating from deregulated oncogenes to p53, because ARF up-regulation is not required for p53 activation after DNA damage and ARFdeficient cells retain sensitivity to DNA damaging agents (Kamijo et al. 1997; Stott et al. 1998).

The work of Ferbeyre and colleagues (Mallette et al. 2007) adds to a body of literature suggesting that this canonical view of oncogene "sensing" is incomplete. Using two distinct senescence-inducing oncogenes, STAT5A and RasV12, they show that deregulated oncogene expression is accompanied by the presence of DNA damage foci. Importantly, they show that these foci are relevant to senescence induction. Inhibiting DNA damage signaling via suppression of ATM can phenocopy the effect of p53 inactivation and, in the presence of a concurrent inhibition of the $\mathrm{Rb}$ tumor suppressor, prevent oncogene-induced senescence. Thus, DNA damage signaling contributes to oncogene-induced senescence.

Importantly, this work provides compelling evidence that oncogene-induced senescence may share a common underlying etiology with other forms of cellular senescence-namely, DNA damage (Fig. 1). Senescence was first characterized as an irreversible cell cycle arrest resulting from the replicative exhaustion of cultured human cells (Hayflick and Moorhead 1961). It is now known that replicative senescence occurs as a consequence of telomere erosion following the passaging of cultured cells (Harley et al. 1990). Critically short telomeres are recognized as DNA breaks, and initiate a DNA damage response resulting in cytostasis (d'Adda di Fagagna et al. 2003). Additionally, $\gamma$-irradiation and genotoxic drugs, like etoposide and cyclophosphamide, 


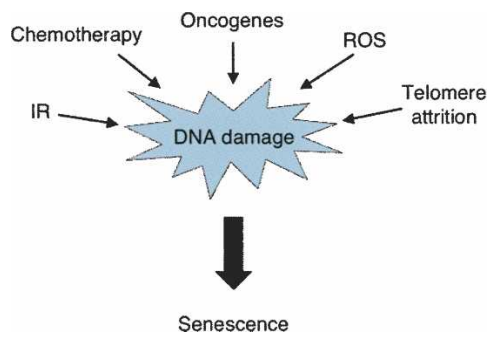

Figure 1. DNA damage as a common mediator of senescence signaling. Ionizing radiation (IR), genotoxic chemotherapy, ROS, telomere attrition, and oncogenes all promote senescence through the induction of DNA damage.

can also induce cellular senescence through the introduction of DNA damage (Wahl and Carr 2001; Schmitt et al. 2002). While oncogene-induced senescence was initially thought to occur in the absence of DNA doublestrand breaks (DSBs), it is now apparent that all forms of cellular senescence may require the activation of the cellular DNA damage response.

However, the mechanism by which deregulated oncogenes induce DNA damage remains unclear. One possibility involves an increase in cellular levels of reactive oxygen species (ROS). Deregulated oncogenes, including Ras, are known to induce ROS, which can result in oxidative base damage and DNA single- and double-strand breaks (Lee et al. 1999; Vafa et al. 2002). Support for this hypothesis comes from experiments showing impaired Ras-induced senescence in the presence of low oxygen (and decreased ROS). However, other possible mechanisms may also account for the persistent presence of DNA damage foci, including oncogene-induced replication stress or impaired DNA repair. Importantly, not all oncogenes effectively induce DNA damage. For example, Ferbeyre and colleagues (Mallette et al. 2007) show that E1A expression, alone or in combination with RasV12 or STAT5A, fails to increase the number of DNA damage foci. Additionally, not all oncogene-induced DNA damage is the same. RasV12 and STAT5A overexpression produce distinct phosphorylation patterns on Chk2, a key mediator of the DNA damage response. Thus, oncogene-induced DNA damage may arise from distinct mechanisms that vary depending on the specific oncogene, the level of oncogene expression and cellular context.

\section{What about ARF?}

How can we reconcile this newfound relevance of oncogene-induced DNA damage in senescence induction with decisive mouse genetic studies showing a central role for ARF in oncogene-induced senescence? One possibility is that ARF is a potent mediator of oncogenic signaling in mice, but not humans. Notably, ARF is not induced in response to deregulated Ras in human cells to the same extent as it is in mouse (Brookes et al. 2002). Additionally, while ARF is highly expressed in senescent mouse fibroblasts, it is generally not abundant in senes- cent human cells (Wei et al. 2001). However, ARF inactivation does occur during Ras-induced transformation of human diploid fibroblasts, suggesting that ARF plays a role in Ras signaling in human cells (Drayton et al. 2003). A second possibility is that while the DNA damage-dependent activation of p53 does not require ARF, the presence of ARF may increase p53 stabilization and activity following DNA damage. Importantly, human and mouse $\mathrm{ARF}$ are induced in response to ionizing radiation (Khan et al. 2000, 2004), and can modulate p53 activity in the presence of DNA damage. Whether ARF could play a similar role in the presence of low-level oncogene-induced DNA damage remains unclear.

Finally, oncogenes may promote senescence through the independent induction of both ARF and DNA damage. While it is well established that oncogenes promote transformation through the combined activation of multiple mitogenic effector pathways, recent work suggests that oncogenes may also engage multiple parallel tumor suppressor pathways. For example, deregulated Myc antagonizes Bcl-2 function and promotes apoptosis through the induction of two distinct tumor suppressors, p53 and the proapoptotic $\mathrm{BH} 3$-only protein Bim (Hemann et al. 2005). Similarly, p53 activation in senescence may involve signaling through both ARF and ATM. Of note, Ferbeyre and colleagues (Mallette et al. 2007) show that E2F1-dependent senescence is suppressed in the absence of ATM, yet the level of senescence in these cells remains higher than that seen in the absence of p53. Perhaps, the combined repression of ATM and ARF in these cells would phenocopy the effects of p53 loss.

Additionally, while multiple parallel pathways can lead to p53 activation, p53 induction represents just one of several parallel pathways leading to senescence. Ferbeyre and colleagues (Mallette et al. 2007) describe an oncogenic gradient-involving E2F1, STAT5A, and Ras-in which increasing the strength of the oncogenic "signal" results in the activation of additional tumor suppressor pathways. E2F1-induced senescence is mediated by p53 activation, while STAT5A-induced senescence involves the combined activation of the p53 and p16/Rb pathways. Finally, Ras-induced senescence involves the activation of the $\mathrm{p} 53$ and $\mathrm{p} 16 / \mathrm{Rb}$ pathways, as well as an additional, uncharacterized, tumor suppressor pathway. Interestingly, the number of senescence pathways engaged by a given oncogene correlates with the relative ability of that oncogene to induce DNA damage foci. Thus, the amount of oncogene-induced damage may determine both the propensity of a cell to enter senescence, as well as the stability of the resulting senescent state.

\section{Oncogene-induced DNA damage and chromatin changes in senescence}

The ability of oncogene-induced DNA damage to promote cellular senescence may simply arise from the continuous DNA damage-dependent activation of the p53 and $\mathrm{p} 16 / \mathrm{Rb}$ pathways. Alternatively, oncogene-induced 
damage may promote senescence progression more directly by affecting chromatin structure. Specifically such damage may nucleate the formation of senescence-associated heterochromatic foci (SAHFs) (Narita et al. 2003). SAHFs are formed by global chromatin structural changes during senescence, resulting in widespread epigenetic changes in gene expression in senescent cells and silencing of cell cycle genes. Interestingly, it has been shown that DNA DSBs in Saccharomyces cerevesiae result in the redistribution of Sir-Ku heterochromatic "gene silencing" complexes from subtelomeric heterochromatin to the sites of DNA damage (Martin et al. 1999; Mills et al. 1999). This relocalization of heterochromatic complex requires MEC1, a yeast homolog of ATM, and causes a transcriptional derepression of genes in subtelomeric regions and the silencing of genes located near DSBs.

Another potential link between DNA damage and chromatin regulation exists in Schizosaccharomyces pombe (Sanders et al. 2004). SET9, the yeast homolog of the mammalian histone methyl-transferase SUV4-20H, mediates histone H4 Lys20 methylation. Interestingly, this SET9-mediated histone H4 Lys20 methylation is required for the DNA damage response in $S$. pombe. Furthermore, upon DNA damage, histone H4 Lys20 methylation recruits Crb2, the yeast counterpart of p53BP1, to sites of DNA damage. While SET9-mediated histone H4 Lys20 methylation does not play a significant role in the regulation of gene expression or heterochromatin function in yeast, SUV4-20H-catalyzed histone $\mathrm{H} 4$ Lys20 trimethylation is involved in gene silencing and heterochromatin formation in higher eukaryotes. Additionally, SUV4-20H directly associates with $\mathrm{Rb}$, which is a critical regulator of SAHF formation (Gonzalo et al. 2005). Although it is unclear whether histone H4 Lys20 methylation is also involved in DNA damage response in mammals, these observations raise the possibility that DNA damage signals might provoke chromatin redistribution and epigenetic alterations in gene expression.

While there are no data to suggest a functional or physical relationship between DNA damage foci and heterochromatin alterations in senescence, it is tempting to speculate that oncogene-induced DNA damage might play a causative role in SAHF formation. For example, each DNA break might nucleate a SAHF, or DNA damage might induce the redistribution of heterochromatic complexes to the sites of DSBs-or different regions of the genome. Additionally, it has been shown that Ras-induced SAHF formation is largely dependent on $\mathrm{p} 16 / \mathrm{Rb}$, but not p53. Since p53 is similarly dispensable for the formation of oncogene-induced DNA damage foci, it is possible that DNA damage foci might trigger SAHF formation cooperatively with the p16 pathway (Fig. 2).

There is, however, evidence to suggest that oncogeneinduced DNA damage and SAHF formation represent distinct processes. For example, STAT5A does not induce obvious SAHF formation or p16 induction (G. Ferbeyre, pers. comm.). In addition, during DNA damage-

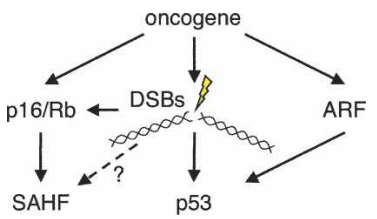

Figure 2. A model for oncogene action in senescence. Deregulated oncogene expression induces p53 and p16 through DNA damage-dependent and -independent pathways. p16/Rb action promotes the formation of stable SAHFs, a process that may be enhanced in the presence of DNA damage foci.

induced senescence, the kinetics of the formation of DNA damage foci and SAHFs are completely different, although the persistent presence of oncogene-induced DNA damage foci might result in the delayed appearance of SAHFs. Interestingly, however, the intensity of SAHF formation is different depending on the senescence stimulus and the cell type. Although SAHFs are induced by a variety of stimuli, including oncogenic Ras, oxidative stress, and DNA damage, oncogenic Ras induces SAHFs most prominently. Ferbeyre and colleagues (Mallette et al. 2007) show that the number of DNA damage foci is also different among distinct oncogenic stimuli, with oncogenic Ras inducing the highest number of foci. Thus, there might be a threshold level of DNA damage above which SAHF formation is triggered. Precise kinetics of DNA damage foci and SAHF formation during Rasinduced senescence, and a detailed spatial comparison between those structures would help to address this question.

\section{Oncogene-induced DNA damage and cancer progression}

While it remains to be determined whether Ras or STAT5-induced DNA damage and senescence occur in vivo, the work of Ferbeyre and colleagues (Mallette et al. 2007) is particularly interesting in light of recent studies concerning early tumor development. First, DNA damage foci have been identified in early tumor precursor lesions, and are proposed to occur as a consequence of activated oncogenes (Bartkova et al. 2005; Gorgoulis et al. 2005). These foci engage a DNA damage response similar to that produced by STAT5 and Ras, including the activation of ATM and Chk2. Second, there is now compelling evidence that oncogene-induced senescence serves as a barrier to early tumor development. Multiple groups have described the presence of pretumorigenic lesions, including melanocytic nevi, lung adenomas, and hyperplastic prostate tissue, which express established senescence markers (Braig et al. 2005; Chen et al. 2005; Collado et al. 2005; Michaloglou et al. 2005). Thus, oncogene-induced DNA damage may contribute to the oncogene-induced senescence seen in early preneoplastic lesions.

Importantly, if oncogene-induced DNA damage is a hallmark of premalignant lesions, then tumor progression in the presence of a potent oncogene may require 
the inactivation of DNA damage response pathways. Consequently, overcoming the barrier to early tumor progression may be quite difficult, as it would require the concurrent inactivation of DNA damage-dependent and -independent senescence-inducing pathways. It is, however, interesting to note that once this barrier is overcome, oncogene-induced DNA damage may promote the acquisition of mutations that enhance tumor progression. Further work will be required to understand how cells expressing deregulated oncogenes bypass senescence during tumor development, and whether the genetic alterations necessary for this senescence bypass play subsequent roles in tumor growth and therapeutic response.

\section{References}

Bartkova, J., Horejsi, Z., Koed, K., Kramer, A., Tort, F., Zieger, K., Guldberg, P., Sehested, M., Nesland, J.M., Lukas, C., et al. 2005. DNA damage response as a candidate anti-cancer barrier in early human tumorigenesis. Nature 434: 864-870.

Braig, M., Lee, S., Loddenkemper, C., Rudolph, C., Peters, A.H., Schlegelberger, B., Stein, H., Dorken, B., Jenuwein, T., and Schmitt, C.A. 2005. Oncogene-induced senescence as an initial barrier in lymphoma development. Nature 436: 660-665.

Brookes, S., Rowe, J., Ruas, M., Llanos, S., Clark, P.A., Lomax, M., James, M.C., Vatcheva, R., Bates, S., Vousden, K.H., et al. 2002. INK4a-deficient human diploid fibroblasts are resistant to RAS-induced senescence. EMBO J. 21: 2936-2945.

Chen, Z., Trotman, L.C., Shaffer, D., Lin, H.K., Dotan, Z.A., Niki, M., Koutcher, J.A., Scher, H.I., Ludwig, T., Gerald, W., et al. 2005. Crucial role of p53-dependent cellular senescence in suppression of Pten-deficient tumorigenesis. $\mathrm{Na}$ ture 436: 725-730.

Collado, M., Gil, J., Efeyan, A., Guerra, C., Schuhmacher, A.J., Barradas, M., Benguria, A., Zaballos, A., Flores, J.M., Barbacid, M., et al. 2005. Tumour biology: Senescence in premalignant tumours. Nature 436: 642.

d'Adda di Fagagna, F., Reaper, P.M., Clay-Farrace, L., Fiegler, H., Carr, P., Von Zglinicki, T., Saretzki, G., Carter, N.P., and Jackson, S.P. 2003. A DNA damage checkpoint response in telomere-initiated senescence. Nature 426: 194-198.

de Stanchina, E., McCurrach, M.E., Zindy, F., Shieh, S.Y., Ferbeyre, G., Samuelson, A.V., Prives, C., Roussel, M.F., Sherr, C.J., and Lowe, S.W. 1998. E1A signaling to p53 involves the p19(ARF) tumor suppressor. Genes \& Dev. 12: 2434-2442.

Drayton, S., Rowe, J., Jones, R., Vatcheva, R., Cuthbert-Heavens, D., Marshall, J., Fried, M., and Peters, G. 2003. Tumor suppressor p16INK4a determines sensitivity of human cells to transformation by cooperating cellular oncogenes. Cancer Cell 4: 301-310.

Evan, G.I., Wyllie, A.H., Gilbert, C.S., Littlewood, T.D., Land, H., Brooks, M., Waters, C.M., Penn, L.Z., and Hancock, D.C. 1992. Induction of apoptosis in fibroblasts by c myc protein. Cell 69: 119-128.

Gonzalo, S., Garcia-Cao, M., Fraga, M.F., Schotta, G., Peters, A.H., Cotter, S.E., Eguia, R., Dean, D.C., Esteller, M., Jenuwein, T., et al. 2005. Role of the RB1 family in stabilizing histone methylation at constitutive heterochromatin. Nat. Cell Biol. 7: 420-428.

Gorgoulis, V.G., Vassiliou, L.V., Karakaidos, P., Zacharatos, P., Kotsinas, A., Liloglou, T., Venere, M., Ditullio Jr., R.A., Kastrinakis, N.G., Levy, B., et al. 2005. Activation of the DNA damage checkpoint and genomic instability in human pre- cancerous lesions. Nature 434: 907-913.

Harley, C.B., Futcher, A.B., and Greider, C.W. 1990. Telomeres shorten during ageing of human fibroblasts. Nature 345: $458-460$.

Hayflick, L. and Moorhead, P.S. 1961. The serial cultivation of human diploid cell strains. Exp. Cell Res. 25: 585-621.

Hemann, M.T., Bric, A., Teruya-Feldstein, J., Herbst, A., Nilsson, J.A., Cordon-Cardo, C., Cleveland, J.L., Tansey, W.P., and Lowe, S.W. 2005. Evasion of the p53 tumor surveillance network by tumor-derived myc mutants. Nature 436: 807811.

Kamijo, T., Zindy, F., Roussel, M.F., Quelle, D.E., Downing, J.R., Ashmun, R.A., Grosveld, G., and Sherr, C.J. 1997. Tumor suppression at the mouse INK4a locus mediated by the alternative reading frame product p19ARF. Cell 91: 649-659.

Khan, S.H., Moritsugu, J., and Wahl, G.M. 2000. Differential requirement for p19ARF in the p53-dependent arrest induced by DNA damage, microtubule disruption, and ribonucleotide depletion. Proc. Natl. Acad. Sci. 97: 3266-3271.

Khan, S., Guevara, C., Fujii, G., and Parry, D. 2004. p14ARF is a component of the p53 response following ionizing irradiation of normal human fibroblasts. Oncogene 23: 6040-6046.

Lee, A.C., Fenster, B.E., Ito, H., Takeda, K., Bae, N.S., Hirai, T., Yu, Z.X., Ferrans, V.J., Howard, B.H., and Finkel, T. 1999. Ras proteins induce senescence by altering the intracellular levels of reactive oxygen species. J. Biol. Chem. 274: 79367940.

Lowe, S.W. and Ruley, H.E. 1993. Stabilization of the p53 tumor suppressor is induced by adenovirus $5 \mathrm{E} 1 \mathrm{~A}$ and accompanies apoptosis. Genes \& Dev. 7: 535-545.

Lowe, S., Cepero, E., and Evan, G. 2004. Tumor surveillance mechanisms. Nature 432: 307-315.

Mallette, F.A., Gaumont-Leclerc, M.-F., and Ferbeyre, G. 2007. The DNA damage signaling pathway is a critical mediator of oncogene-induced senescence. Genes \& Dev. (this issue).

Martin, S.G., Laroche, T., Suka, N., Grunstein, M., and Gasser, S.M. 1999. Relocalization of telomeric Ku and SIR proteins in response to DNA strand breaks in yeast. Cell 97: 621-633.

Michaloglou, C., Vredeveld, L.C., Soengas, M.S., Denoyelle, C., Kuilman, T., van der Horst, C.M., Majoor, D.M., Shay, J.W., Mooi, W.J., and Peeper, D.S. 2005. BRAFE600 associated senescence-like cell cycle arrest of human naevi. Nature 436: $720-724$

Mills, K.D., Sinclair, D.A., and Guarente, L. 1999. MEC1-dependent redistribution of the Sir3 silencing protein from telomeres to DNA double-strand breaks. Cell 97: 609-620.

Narita, M., Nunez, S., Heard, E., Lin, A.W., Hearn, S.A., Spector, D.L., Hannon, G.J., and Lowe, S.W. 2003. Rb-mediated heterochromatin formation and silencing of E2F target genes during cellular senescence. Cell 113: 703-716.

Palmero, I., Pantoja, C., and Serrano, M. 1998. p19ARF links the tumour suppressor p53 to Ras. Nature 395: 125-126.

Sanders, S.L., Portoso, M., Mata, J., Bahler, J., Allshire, R.C., and Kouzarides, T. 2004. Methylation of histone H4 lysine 20 controls recruitment of $\mathrm{Crb} 2$ to sites of DNA damage. Cell 119: 603-614.

Schmitt, C.A., Fridman, J.S., Yang, M., Lee, S., Baranov, E., Hoffman, R.M., and Lowe, S.W. 2002. A senescence program controlled by p53 and p16INK4a contributes to the outcome of cancer therapy. Cell 109: 335-346.

Serrano, M., Lin, A.W., McCurrach, M.E., Beach, D., and Lowe, S.W. 1997. Oncogenic ras provokes premature cell senescence associated with accumulation of p53 and p16INK4a Cell 88: 593-602.

Stott, F.J., Bates, S., James, M.C., McConnell, B.B., Starborg, M., Brookes, S., Palmero, I., Ryan, K., Hara, E., Vousden, K.H., et 
al. 1998. The alternative product from the human CDKN2A locus, p14(ARF), participates in a regulatory feedback loop with p53 and MDM2. EMBO J. 17: 5001-5014.

Vafa, O., Wade, M., Kern, S., Beeche, M., Pandita, T.K., Hampton, G.M., and Wahl, G.M. 2002. c-Myc can induce DNA damage, increase reactive oxygen species, and mitigate p53 function: A mechanism for oncogene-induced genetic instability. Mol. Cell 9: 1031-1044.

Wahl, G.M. and Carr, A.M. 2001. The evolution of diverse biological responses to DNA damage: Insights from yeast and p53. Nat. Cell Biol. 3: 277-286.

Wei, W., Hemmer, R.M., and Sedivy, J.M. 2001. Role of p14(ARF) in replicative and induced senescence of human fibroblasts. Mol. Cell. Biol. 21: 6748-6757.

Zindy, F., Eischen, C.M., Randle, D.H., Kamijo, T., Cleveland, J.L., Sherr, C.J., and Roussel, M.F. 1998. Myc signaling via the ARF tumor suppressor regulates p53 dependent apoptosis and immortalization. Genes \& Dev. 12: 2424-2433. 


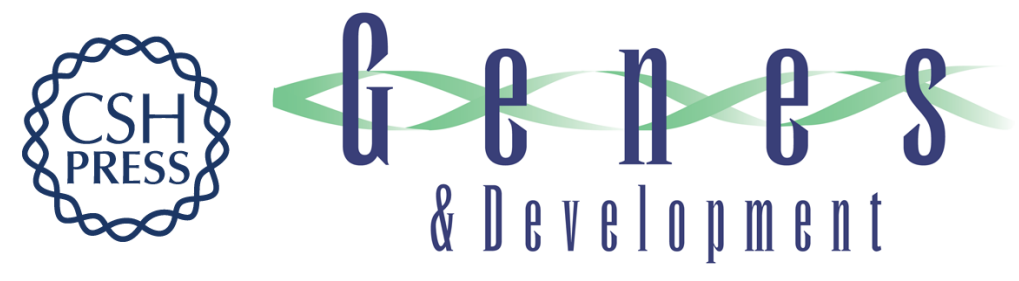

\section{Oncogenes and senescence: breaking down in the fast lane}

Michael T. Hemann and Masashi Narita

Genes Dev. 2007, 21:

Access the most recent version at doi:10.1101/gad.1514207
Related Content The DNA damage signaling pathway is a critical mediator of oncogene-induced senescence
Frédérick A. Mallette, Marie-France Gaumont-Leclerc and Gerardo Ferbeyre
Genes Dev. January, 2007 21: 43-48

References This article cites 32 articles, 8 of which can be accessed free at:

http://genesdev.cshlp.org/content/21/1/1.full.html\#ref-list-1

Articles cited in:

http://genesdev.cshlp.org/content/21/1/1.full.html\#related-urls

\section{License}

Email Alerting

Service

Receive free email alerts when new articles cite this article - sign up in the box at the top right corner of the article or click here.

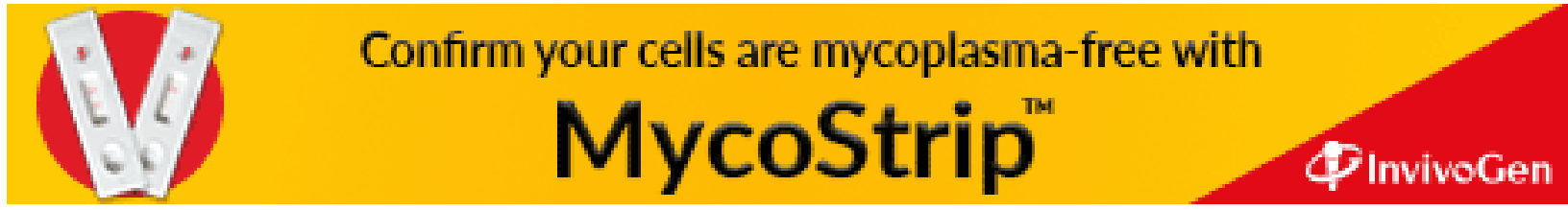

